\title{
Application of Thermotropic Compositions for EOR with Cyclic-Steam Stimulation at Permian-Carboniferous Deposit of Usinsk Oilfield
}

\author{
Liubov K. Altunina, \\ Vladimir A. Kuvshinov and Ivan V. Kuvshinov* \\ Institute of Petroleum Chemistry SB RAS \\ 4 Akademichesky, Tomsk, 634055, Russia
}

Received 20.12.2018, received in revised form 19.01.2019, accepted 04.02.2019

The use of thermotropic chemical compositions for enhanced oil recovery in combination with cyclicsteam stimulation (CSS), in the Permian-Carboniferous deposit of the Usinsk high-viscosity oil field, Komi Republic, Russia, is considered. Among the wells under consideration there are both wells treated only with steam, and in combination with two types of chemical compositions, oil-displacing and flow-diverting. A comparison of the CSS effect for wells, where this treatment is used for the first time, with wells with multiple CSS, from two to ten times, has been carried out. It was concluded that the first cycle of the CSS is most effective for the wells just put into operation, and the use of chemical compositions is not necessary, however, for subsequent cycles it is recommended to use chemical compositions that will ensure additional residual oil recovery and reduction of production watercut.

Keywords: Permian-Carboniferous deposits, Usinsk oilfield, thermotropic chemical compositions, enhanced oil recovery, cyclic-steam stimulation.

Citation: Altunina L.K., Kuvshinov V.A., Kuvshinov I.V. Application of thermotropic compositions for EOR with cyclicsteam stimulation at permian-carboniferous deposit of Usinsk oilfield, J. Sib. Fed. Univ. Chem., 2019, 12(1), 136-143. DOI: 10.17516/1998-2836-0113.

\footnotetext{
(C) Siberian Federal University. All rights reserved

* Corresponding author E-mail address: alk@ipc.tsc.ru; kiv@ipc.tsc.ru
} 


\title{
Применение термотропных композиций
}

\section{для увеличения нефтеотдачи}

при пароциклических обработках скважин

\section{на пермо-карбоновой залежи \\ Усинского месторождения}

\author{
Л.К. Алтунина, В.А. Кувшинов, И.В. Кувшинов \\ Институт химии нефти СО РАН \\ Россия, 634055, Томск, пр. Академический, 4
}

\begin{abstract}
Рассмотрено применение термотропныххимических композиций для повымения нефтеотдачи совместно с парочиклическими обработками (ПЦО) на пермо-карбоновой залежи Усинского месторождения высоковязкой нефти, Республика Коми, Россия. Среди рассматриваемых скважин присутствуют как скважины, обрабатываемые только паром, так и в комбинации с химическими композициями двух типов, нефтевытесняющими и потокоотклоняющими. Проведено сравнение эффекта ПЦО для скважин, где такая обработка применяется впервые, со скважинами с многократной ПЦО, от двух до десяти раз. Сделан вывод о том, что для вводимых в эксплуатацию скважин первый цикл ПЦО наиболее эффективен и применение химических композищий не является необходимым, однако для последуюших ииклов рекомендуется применять химические композиции, которые будут обеспечивать доотмыв остаточной нефти и снижение обводненности продукции.
\end{abstract}

Ключевые слова: пермо-карбоновая залежь высоковязкой нефти Усинского месторождения, пароциклическая обработка, термотропные химические композиции, повымение нефтеотдачи.

\section{Введение}

В настоящее время одними из наиболее широко применяемых методов разработки месторождений высоковязкой нефти являются термические методы, в основном закачка пара, как постоянная, или площадная, через нагнетательные скважины, так и циклическая закачка в добывающие скважины, так называемая пароциклическая обработка (ПЦО). Пермо-карбоновая залежь Усинского месторождения в Республике Коми, разработка которой анализируется в данной работе, является характерным объектом для применения термических методов добычи. По данным добывающей компании ООО «ЛУКОЙЛ-Коми», отмечается ежегодное увеличение количества проводимых скважинно-операций, сопровождающееся ростом дополнительной добычи нефти. В последние годы совместно с ПЦО широко применяются физико-химические методы увеличения нефтеотдачи. В данной статье рассматриваются различные термотропные композиции, разработанные ИХН СО РАН [1], которые условно можно разделить на два класса: гелеобразующие и нефтеотмывающие. Гелеобразующие композиции способствуют сниже- 
нию обводненности продукции и увеличению охвата пласта паротепловым воздействием, а нефтеотмывающие увеличивают добычу нефти. Для термотропных композиций активация их функций происходит под воздействием температуры, в данном случае пара от ПЦО, что формирует комплексное паротепловое и физико-химическое воздействие на пласт. Далее будут рассмотрены различные случаи применения композиций и их эффективность в зависимости от повторения циклов ПЦО. Под применением химических композиций понимается приготовление и закачка в скважину водного раствора неорганических или полимерных реагентов. В данной статье рассматриваются два типа таких композиций: гелеобразующая (потокоотклоняющая) композиция ГАЛКА и нефтевытесняющая композиция НИНКА, разработанные в ИХН СО РАН. Далее в статье композиции упоминаются под соответствующими условными наименованиями.

\section{Описание объекта разработки}

Пермо-карбоновая залежь Усинского месторождения (рис. 1) находится в интервале глубин 1100-1500 м. При начальных условиях нефть пермо-карбоновой залежи характеризуется высокими значениями динамической вязкости, около 710 мПа·с, из-за большого содержания асфальто-смолистых компонентов. Пермо-карбоновые отложения имеют крайне неоднородное геологическое строение, пласты-коллекторы сложного типа: каверно-поровые, трещиннопоровые, трещинно-каверно-поровые. Текущее состояние разработки залежи характеризуется высокой степенью обводненности добываемой продукции при низкой освоенности геологических запасов нефти [2], что создает предпосылки для использования различных методов увеличения нефтеотдачи, в частности для применения химических композиций. Поскольку средняя температура пласта составляет $23^{\circ} \mathrm{C}$, на месторождении широко применяются термические методы добычи.

\section{Химические композиции, применяемые совместно с ПЦО}

Гелеобразующая композиция ГАЛКА на основе системы «соль алюминия - карбамид вода» применяется для увеличения охвата пласта при заводнении, паротепловом и пароциклическом воздействии, достигаемого закачкой через водонагнетательные, паронагнетательные

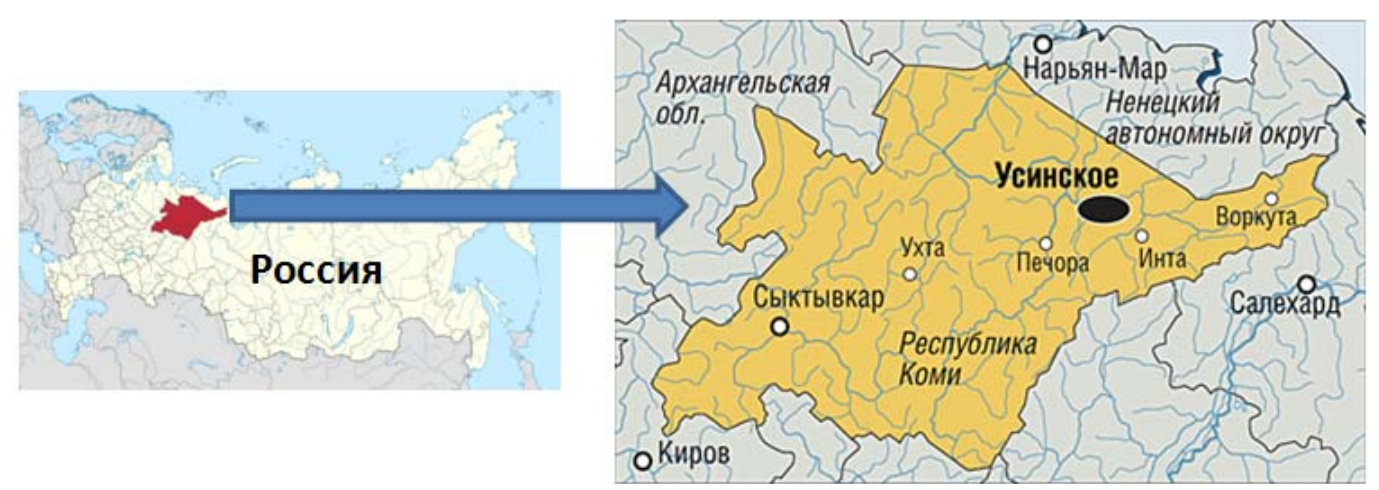

Рис. 1. Усинское месторождение, Республика Коми, Россия

Fig. 1. Usinsk oilfield, the Republic of Komi, Russia 
или пароциклические скважины водных растворов химреагентов, способных образовывать гели гидроксида алюминия непосредственно в пластовых условиях под действием тепловой энергии пласта или закачиваемого теплоносителя. Образующиеся в пласте гели сдерживают прорыв воды и пара из нагнетательных в добывающие скважины, перераспределяют фильтрационные потоки пластовых флюидов, что отражается на стабилизации либо снижении обводненности продукции окружающих добывающих или пароциклических скважин, увеличении добычи нефти.

Нефтевытесняющая композиция НИНКА - это состав на основе ПАВ, который в пласте под действием теплоносителя образует $\mathrm{CO}_{2}$ и аммиачную буферную систему $[1,4]$. В скважину перед нагнетанием пара закачивается оторочка композиции на основе системы «ПАВ карбамид - соль аммония - вода». В пласте под действием высокой температуры пара карбамид гидролизуется с образованием углекислого газа и аммиака. В системе нефть - вода нефтяная фаза будет обогащена $\mathrm{CO}_{2}$, водная - аммиаком, который с солью аммония образует щелочную систему с максимальной буферной емкостью в интервале $\mathrm{pH} 9 \div 10$, оптимальную для целей нефтевытеснения.

\section{Анализ промысловых данных}

По общей статистике добывающей компании ООО «ЛУКОЙЛ-Коми», за 2014-2017 гг. средний прирост дебита нефти после ПЦО составляет 15 т/сут. Однако по итогам 2017 года наблюдается некоторый прирост эффективности ПЦО, что обусловлено увеличением доли первичных обработок. Дебиты нефти до обработки очень малы, в среднем 2-4 т/сут, средний прирост дебита нефти после обработки составляет 17.5 т/сут, имеется небольшой процент скважин с отрицательным или нулевым приростом.

Распределение на рис. 2 имеет несимметричный характер, что может объясняться неоднородностью фонда обрабатываемых скважин. Действительно, как показано далее, результаты

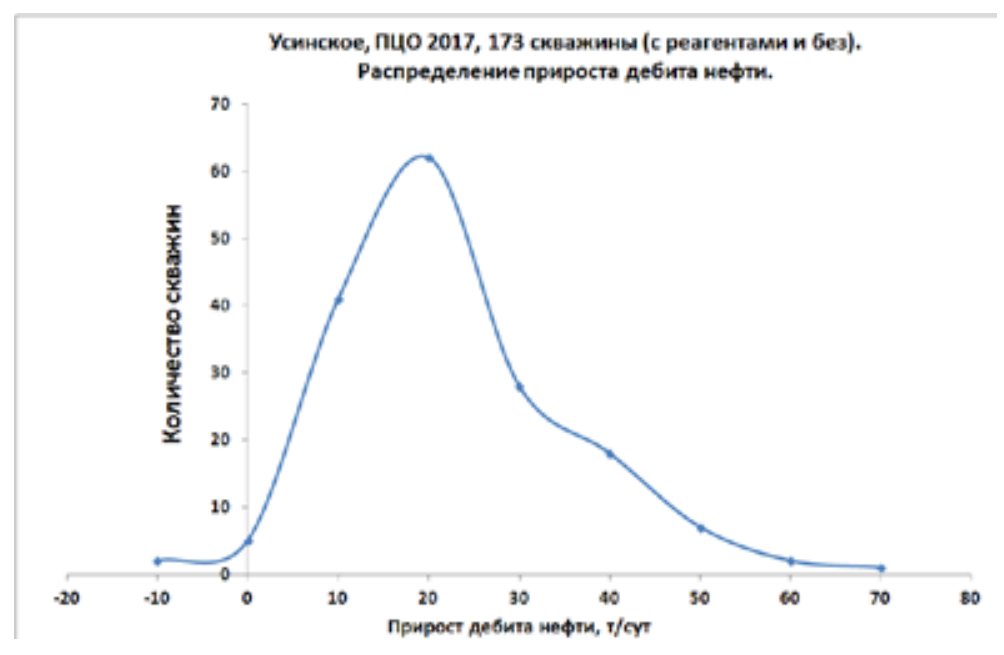

Рис. 2. Распределение прироста дебита нефти по количеству скважин после ПЦО, по всем скважинам за 2017 г.

Fig. 2. Distribution of oil production rate increase by the number of wells after CSS, for all wells for 2017 
Таблица 1. Сравнение эффекта обработок ПЦО с композициями и без реагентов

Table 1. Comparison of the effects of CSS treatments with compositions and without reagents

\begin{tabular}{|c|c|c|c|c|}
\hline Тип обработки & $\begin{array}{c}\text { Прирост дебита } \\
\text { нефти, т/сут }\end{array}$ & $\begin{array}{c}\text { Количество } \\
\text { скважин }\end{array}$ & $\begin{array}{c}\text { Изменение } \\
\text { обводненности, \% }\end{array}$ & Примечание \\
\hline Все ПЦО за 2017 г. & 17.6 & 166 & 10.5 & \\
\hline $\begin{array}{l}\text { Без реагентов } \\
\text { Все ПЦО }\end{array}$ & 24.0 & 64 & 19.8 & $\begin{array}{l}\text { Все, кроме 4-х } \\
\text { скважин - первый } \\
\text { цикл }\end{array}$ \\
\hline $\begin{array}{l}\text { Без реагетнов } \\
\text { Первый цикл - из } \\
\text { бурения }\end{array}$ & 28.0 & 48 & 27.0 & Новые скважины \\
\hline $\begin{array}{l}\text { Без реагетнов } \\
\text { Первый цикл }\end{array}$ & 14.9 & 12 & -10.5 & \\
\hline $\begin{array}{l}\text { Без реагентов } \\
\text { Более } 1 \text { цикла }\end{array}$ & 5.5 & 2 & -22.8 & $\begin{array}{l}\text { Данные работы } \\
\text { были только по } \\
2 \text { скважинам, } 2 \text { и } \\
5 \text { циклов }\end{array}$ \\
\hline $\begin{array}{l}\text { ГАЛКА } \\
\text { Все ПЦО }\end{array}$ & 12.8 & 27 & -18.9 & \\
\hline $\begin{array}{l}\text { ГАЛКА } \\
\text { Первый цикл }\end{array}$ & 16.5 & 9 & -35.7 & \\
\hline $\begin{array}{l}\text { ГАЛКА } \\
\text { Более } 1 \text { цикла }\end{array}$ & 10.9 & 18 & -10.4 & От 2 до 12 циклов \\
\hline $\begin{array}{l}\text { НИНКА } \\
\text { Все ПЦО }\end{array}$ & 14.0 & 74 & 13.4 & \\
\hline $\begin{array}{l}\text { НИНКА } \\
\text { Первый цикл }\end{array}$ & 16.5 & 46 & 19.9 & \\
\hline $\begin{array}{l}\text { НИНКА } \\
\text { Более } 1 \text { цикла }\end{array}$ & 10.9 & 27 & 3.7 & От 2 до 9 циклов \\
\hline
\end{tabular}

ПЦО значительно отличаются для первого цикла обработки и для скважин с многократно повторяющимися циклами закачки пара. В табл. 1 все рассматриваемые обработки скважин разбиты на три группы: без реагентов, с гелеобразующей композицией ГАЛКА и с нефтевытесняющей композицией НИНКА. Внутри каждой группы отдельно рассматриваются первичные обработки (первый цикл ПЦО) и обработки на скважинах, на которых ранее уже проводилась циклическая закачка пара.

Данные, приведенные в табл. 1, позволяют сделать несколько важных выводов. Во-первых, наиболее эффективным является первый цикл пароциклических обработок. Это обусловлено низким коэффициентом извлечения высоковязкой нефти без применения термических методов. Другими словами, при первом цикле ПЦО в зоне охвата тепловым воздействием высокое содержание нефти и низкое содержание воды, что позволяет использовать тепловую энергию пара наиболее эффективно. Во-вторых, первичная пароциклическая обработка, как правило, эффективна и без дополнительных химических реагентов. Далее, с уменьшением содержания нефти и ростом обводненности, в соответствии с кривой на рис. 2, эффективность закачки пара снижается от цикла к циклу (рис. 4). Несмотря на то, что в представленной выборке мало скважин без реагентов и с повторным ПЦО, следует отметить резкое снижение эффек- 
тивности обработок без реагентов для нескольких циклов. На рис. 3 представлена статистика добывающей компании по данному месторождению за 2014-2017 гг., где показано снижение эффективности пароциклических обработок от цикла к циклу для обработок без реагентов и более стабильный прирост дебита нефти при многократных обработках с применением химических композиций. Данные выводы позволяют оптимизировать применение рассматриваемых технологий.

Также следует отметить, что пароциклические обработки ведут к росту обводненности продукции. Это естественный процесс, поскольку, в первую очередь, закачиваемый пар конденсируется в воду и добывается вместе с разжиженной нефтью. При многократных циклах ПЦО формируются промытые зоны и каналы, что ведет к снижению эффективности закачки пара. Однако, как видно из данных табл. 1, применение гелеобразующей композиции может существенно снизить обводненность и, соответственно, увеличить охват пласта при обработке, вовлечь в разработку застойные зоны и увеличить общую эффективность использования пара.

На рис. 4 показан несимметричный характер распределения для обработок первого цикла ПЦО с наличием двойного «горба» распределения, что говорит о неоднородности фонда скважин. Однако для композиции ГАЛКА этой асимметрии не наблюдается. Применение данной композиции усредняет результат обработок, причем в области как малых, так и больших эффектов, что позволяет рекомендовать композицию ГАЛКА для высокообводненных скважин, но делает ее малопригодной для скважин с высоким начальным дебитом нефти при первом цикле ПЦО. Самая высока точка на кривой ГАЛКА на рис. 5 отражает наименьший разброс в результатах обработок с данной композицией. Стабильное снижение обводненности и предсказуемость результатов позволяют рекомендовать эту композицию к использованию на высокообводненных скважинах.

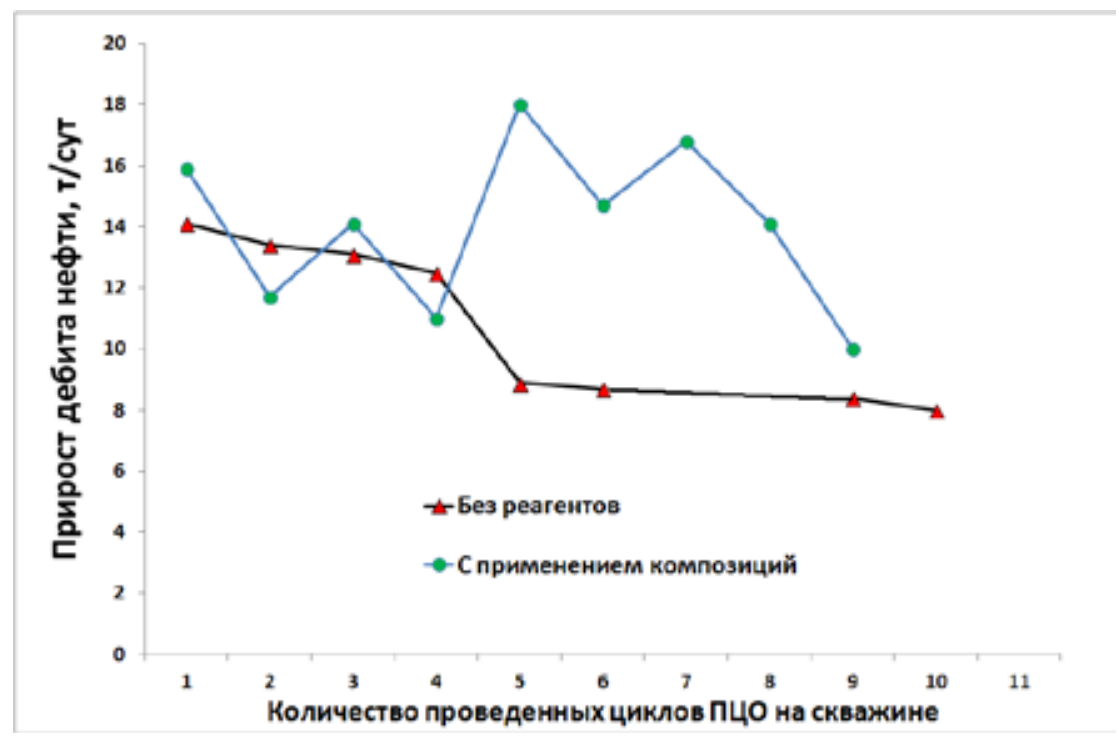

Рис. 3. Зависимость прироста дебита нефти от количества проведенных циклов ПЦО

Fig. 3. Dependence of the increase in oil production rate on the number of conducted cycles of CSS 


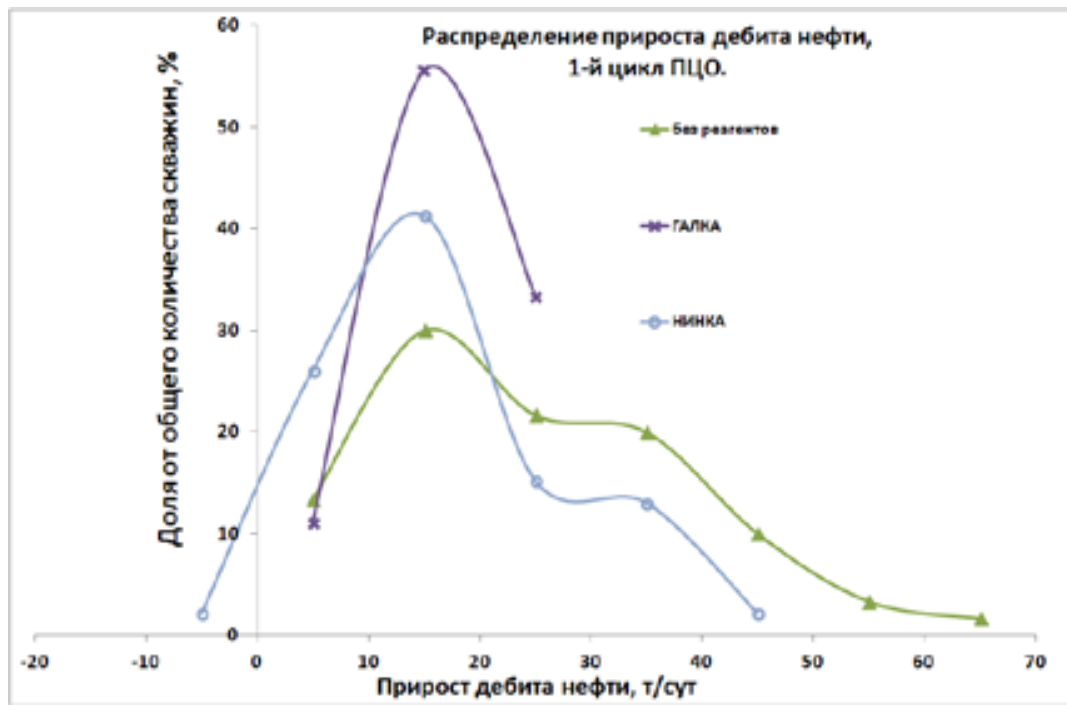

Рис. 4. Распределение доли от общего числа скважин в зависимости от прироста дебита нефти после ПЦО, по обработкам первого цикла за 2017 г.

Fig. 4. The percentage distribution of the total number of wells, depending on the increase in oil production rate after CSS, for the first cycle treatments in 2017

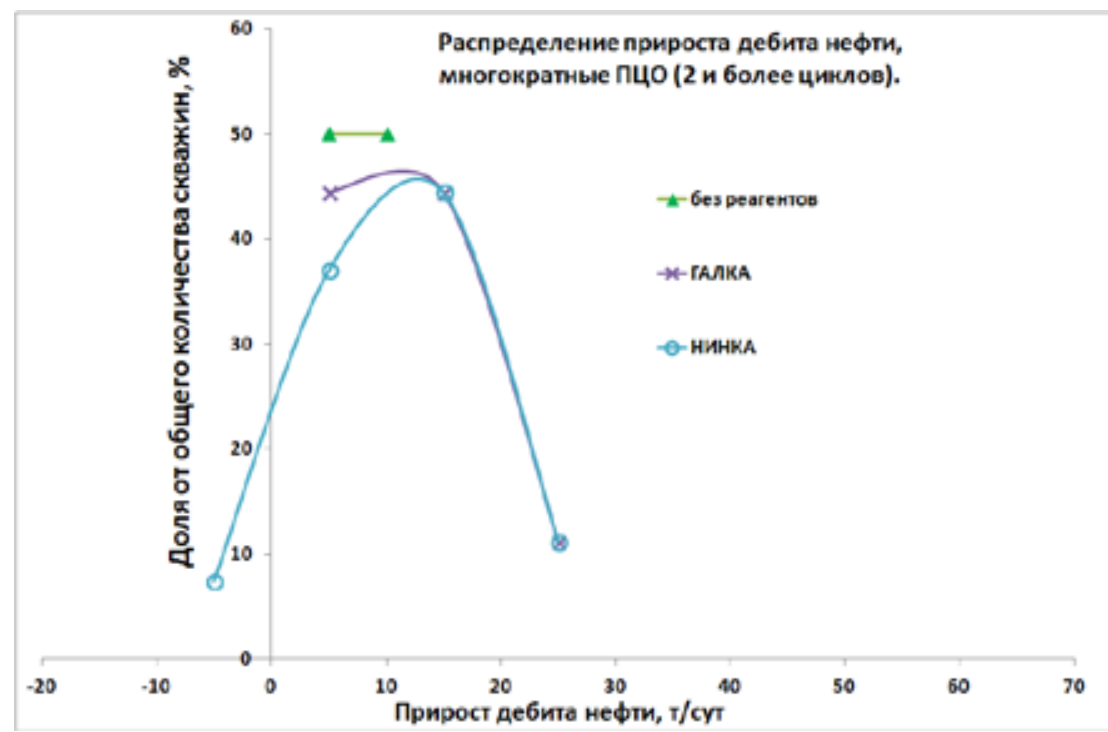

Рис. 5. Распределение прироста дебита нефти по проценту от общего числа скважин после ПЦО, по многократным обработкам за 2017 г.

Fig. 5. The percentage distribution of the total number of wells, depending on the increase in oil production rate after CSS, for multiple treatments for 2017

По рис. 5, несмотря на малое число рассматриваемых скважин, можно сделать вывод, о низкой эффективности применения многократных циклов ПЦО без реагентов. Эффективность композиций ГАЛКА и НИНКА, по данным рис. 5, практически одинакова, и выбор той или иной композиции, соответственно, должен быть обусловлен первоочередностью технологиче- 
ских задач - снижение обводненности или интенсификация добычи. Также при многократных циклах закачки пара исчезает несимметричность распределения, начальные геологические и технологические различия скважин сглаживаются, вероятно, ввиду одинакового механизма формирования промытых зон и каналов при многократных ПЦО.

\section{Выводы}

При многократных ПЦО применение нефтевытесняющих композиций эффективно и обоснованно, поскольку одной из основных заявленных функций таких композиций является именно доотмыв остаточной нефти.

Применение гелеобразующих композиций снижает обводненность продукции, поэтому данный вид комбинированной обработки можно рекомендовать для сильно обводненных скважин.

Выбор той или иной композиции, соответственно, должен быть обусловлен первоочередностью технологических задач - снижением обводненности или интенсификацией добычи.

\section{Список литературы}

1. Altunina L.K., Kuvshinov V.A. Improved Oil Recovery of High-Viscosity Oil Pools with Physicochemical Methods and Thermal-Steam Treatments. Oil \& Gas Science and Technology 2008. Vol. 63(1), P. 37-48.

2. Урсегов С.О. Опыт секторного термогидродинамического моделирования пермокарбоновой залежи Усинского месторождения на основе реализации комплексного подхода. III Международный научный симпозиум «Теория и практика применения методов увеличения нефтеотдачи пластов». Москва, ОАО «ВНИИнефть», 20-21 сентября 2011. [Ursegov S.O. Experience of sector thermohydrodynamic modeling of Permian-Carboniferous deposit of Usinskoye oilfield on the basis of complex approach realization. III International Scientific Symposium "Theory and Practice of Application of Enhanced Oil Recovery Techniques". Moscow, OAO VNIIneft, September 20-21, 2011. (in Russ.)]

3. Рузин Л.М., Чупров И.Ф. Технологические принципы разработки залежей аномально вязких нефтей и битумов. Ухта: УГТУ, 2007. 244 c. [Ruzin L.M., Chuprov I.F. Technological principles for the development of deposits of anomalously viscous oils and bitumens. Ukhta: USTU, 2007. 244 p. (In Russ.)]

4. Алтунина Л.К., Кувшинов В.А., Кувшинов И.В., Стасьева Л.А., Чертенков М.В., Шкрабюк Л.С., Андреев Д.В. Физико-химические и комплексные технологии увеличения нефтеотдачи пермо-карбоновой залежи высоковязкой нефти Усинского месторождения. Нефтяное хозяйство 2017. № 7, C. 26-29. [Altunina L.K., Kuvshinov V.A., Kuvshinov I.V., Stasieva L.A., Chertenkov M.V., Shkrabyuk L.S., Andreev D.V. Physicochemical and complex technologies for increasing the oil recovery of the Permian-Carboniferous deposit of high-viscosity oil from the Usinskoye oilfield. Oil Industry 2017. Vol. 7, P. 26-29. (In Russ.)] 